\title{
Safe at Home with Assistive Technology
}

\section{Ingrid Kollak}

University of Applied Sciences, Berlin, Germany

*Corresponding author: Ingrid Kollak, University of Applied Sciences, Berlin, Germany, Tel: 030 99245409; Fax: 030 99245245; E-mail:kollak@ash-berlin.eu Received date: August 08, 2016, Acc date: September 19, 2016, Pub date: September 26, 2016

Copyright: (c) 2016 Kollak I. This is an open-access article distributed under the terms of the Creative Commons Attribution License, which permits unrestricted use, distribution, and reproduction in any medium, provided the original author and source are credited.

Citation: Kollak I (2016) Safe at Home with Assistive Technology. J Gen Pract (Los Angel) 4: 269. doi1 0.4172/2329-9126.1000269

\section{Book Review}

The book provides an overview of research on assistive technology. However, describes helpful technology which facilitates disabled, old and acutely sick folks to manage their daily lives higher and keep safe within the home. It discusses safety as known from moral, technical and social perspective, and offers samples of the issues that users, their helpers and skilled careers have with helpful technology in everyday life.

Teams from Finland, Germany, Great Britain, Spain, Switzerland and the US detail how frail, handicapped or temporarily sick people can manage their daily life at home with the help of assistive technology. The teams address common problems of getting started with as well as the maintenance of technical devices. They explain advantages as well as limitations. Also describe common demands of the above-mentioned group of people - including their informal and professional helpers.

All chapters focus on safety at home offered through technological solutions, information and telemedicine as well as communication and entertainment. They discuss solutions from ethical, technical and social perspectives. At the same time the book provides lists of useful addresses, websites and literature and uses photographs to illustrate the main topic: how users and technology work together to create safety. Also the book provides insights from user-centred analysis and technology will work along to make sure safety. User-focused and mixing expertise with analysis, the book can interest users of those sorts of technology, health professionals United Nations agency would possibly introduce and dictate them, engineers and designers at United Nations agency develop and sell helpful technological gadgets, and build safe homes still as researchers and also students United Nations agency add these fields. It provides a summary of the present technology, examines ways that to check its effectiveness from the purpose of read of users, health professionals and researchers from totally different fields (architecture, education, engineering, facility management, medicine, nursing, physical therapy, rehabilitative drugs, physiatrist, science and speech therapy), and lists helpful addresses, websites and literature.

The book is written for people using and handling, health professionals introducing and prescribing as well as engineers developing and selling assistive technology. Generally, assistive technology focuses to allow people with disabilities to "involve more fully in all phases of life (home, school, and community)" and increases their possibilities and opportunities for "education, social interactions, and potential for helpful employment. It enables to create greater confidences, independence and control in disabled individuals. Many infants, toddlers and preschoolers, all with some or other kind of developmental, physical, sensory, or cognitive disability, with the use of assistive technology created improvements during their child development which included improvements in various activity such as social, communication, literacy, motor, adaptive, and also increases in engagement and involment in learning activities and practices. 